\title{
Enamine Organocatalysts for the Thiol-Michael Addition Reaction and Cross-linking Polymerizations
}

\author{
Jasmine Sinha ${ }^{¥, \dagger}$, Shafer Soars ${ }^{¥, \$}$, Christopher N. Bowman ${ }^{\dagger *}$ \\ $¥$ - Both authors contributed significantly to this work \\ $\dagger$ - Department of Chemical and Biological Engineering, University of Colorado Boulder, Boulder, CO, United \\ States. \\ \$ - Department of Chemistry, University of Colorado Boulder, Boulder, CO, United States.
}

\section{Supplementary Information}

\section{Contents}

1. NMR Spectra of Model Reactant with 2,4,6-trimethylpyridine...................S2

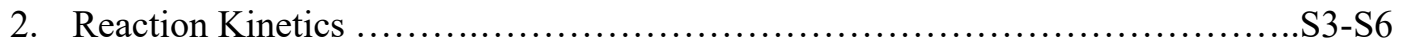

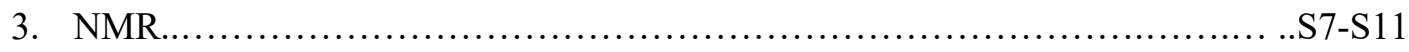




\section{NMR Spectra of Model Reactant with 2,4,6-trimethylpyridine}

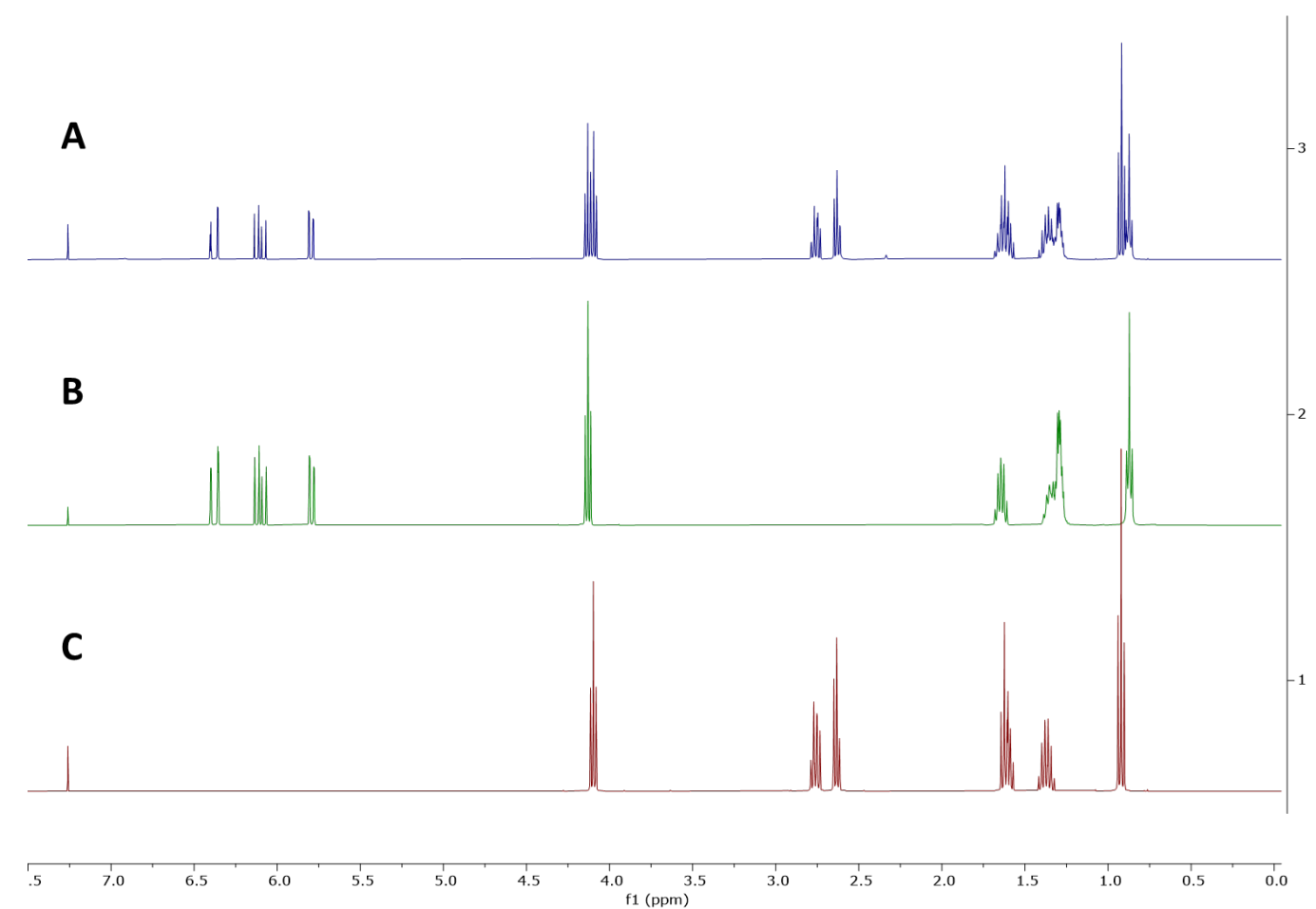

Figure S1. (A) ${ }^{1} \mathrm{H}$ NMR of reaction with n-hexyl acrylate (1 eq.), butyl-3-mercaptopropionate (1 eq.), and a catalytic amount of 2,4,6-trimethylpyridine ( 0.05 eq.) (the reaction was run for $1 \mathrm{hr}$ before taking $1 \mathrm{H}$ NMR). NMR shows no reaction occurring when using a catalytic amount of base with a pKa of 7.5. No reaction with $\mathrm{pKa}$ values similar to enamines employed further demonstrates a nucleophilic pathway by enamines. (B) Starting material ${ }^{1} \mathrm{H}$ NMR of $\mathrm{n}-$ hexyl acrylate. (C) Starting material ${ }^{1} \mathrm{H}$ NMR of butyl-3-mercapropropionate. 


\section{Reaction Kinetics}

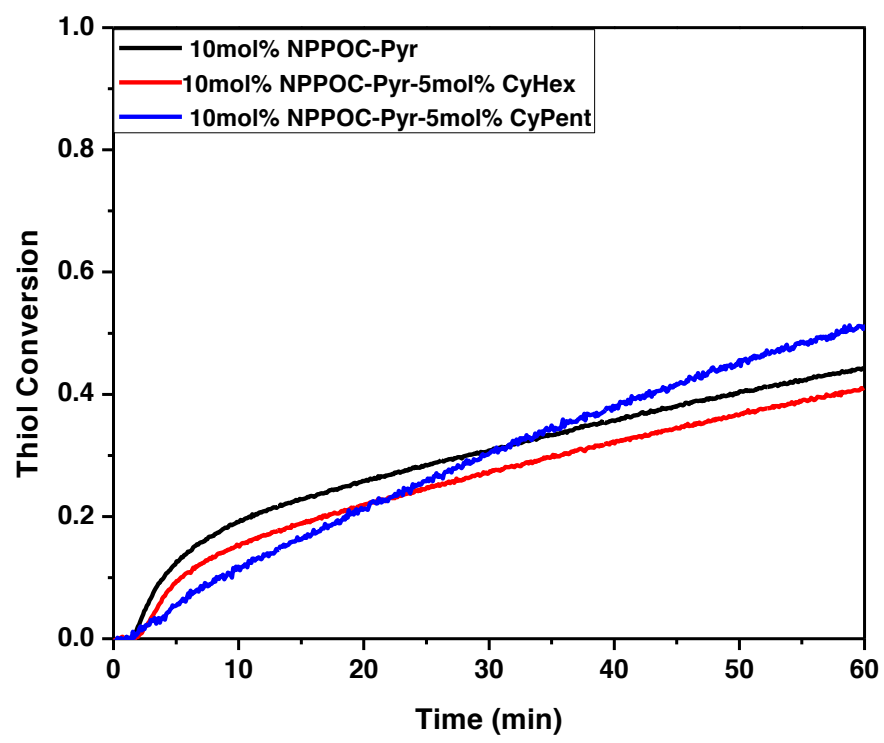

Figure S2. Thiol Conversion versus time as monitored by FT-IR for the model reaction between butyl 3mercaptopropionate (BMP) and 1-hexyl acrylate (HA). Comparison of $10 \mathrm{~mol} \%$ NPPOC-Pyr (NPPOC-Pyrrolidine) with in-situ generation of photobase by using different ring size cycloketone, $10 \mathrm{~mol} \%$ NPPOC-Pyr- $5 \mathrm{~mol} \% \mathrm{CyHex}$ (cyclohexanone) and $10 \mathrm{~mol} \%$ NPPOC-Pyr-5 mol\% CyPent (cyclopentanone). The mixture consists of initial stoichiometric ratio of 1:1 thiol to vinyl functional group concentrations. Each sample was stabilized in the dark for 1 min and then irradiated with $50 \mathrm{~mW} / \mathrm{cm}^{2} 365 \mathrm{~nm}$ wavelength at ambient temperature.

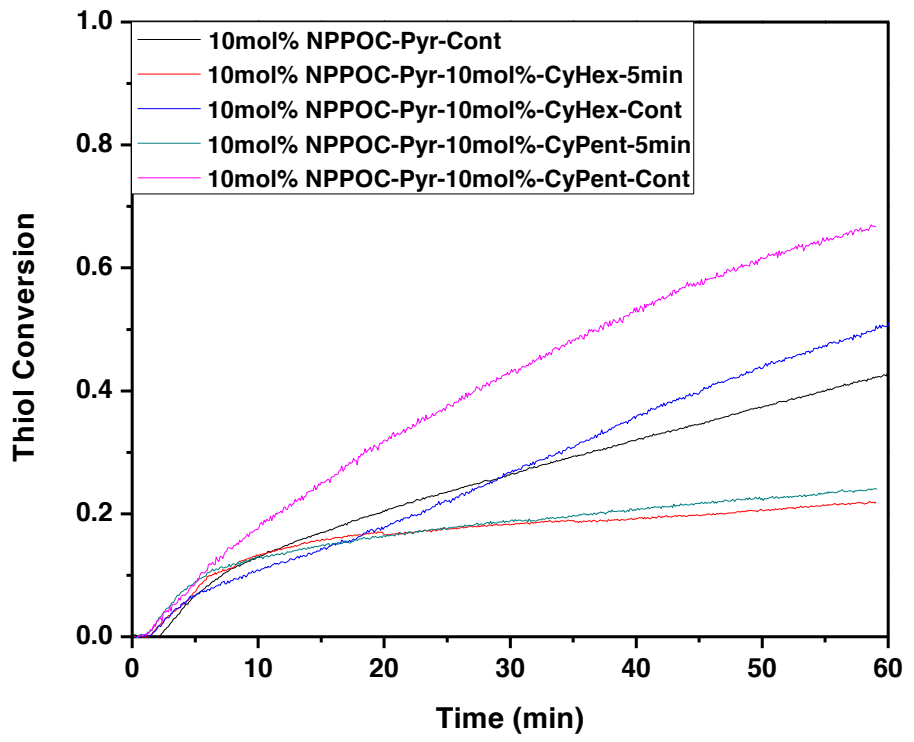

Figure S3. $10 \mathrm{~mol} \%$ of NPPOC-Pyr and its comparison in the presence of $10 \mathrm{~mol} \%$ NPPOC-Pyr-5 mol\%CyHex (cyclohexanone) and $10 \mathrm{~mol} \%$ NPPOC-Pyr-5 mol\% CyPent (cyclopentanone) irradiating for 5 minutes and irradiating continuously for 60 minutes. The mixture consists of initial stoichiometric ratio of 1:1 thiol to vinyl functional group concentrations. Each sample was stabilized in the dark for 1 min and then irradiated with $50 \mathrm{~mW} / \mathrm{cm}^{2} 365 \mathrm{~nm}$ wavelength at ambient temperature. 


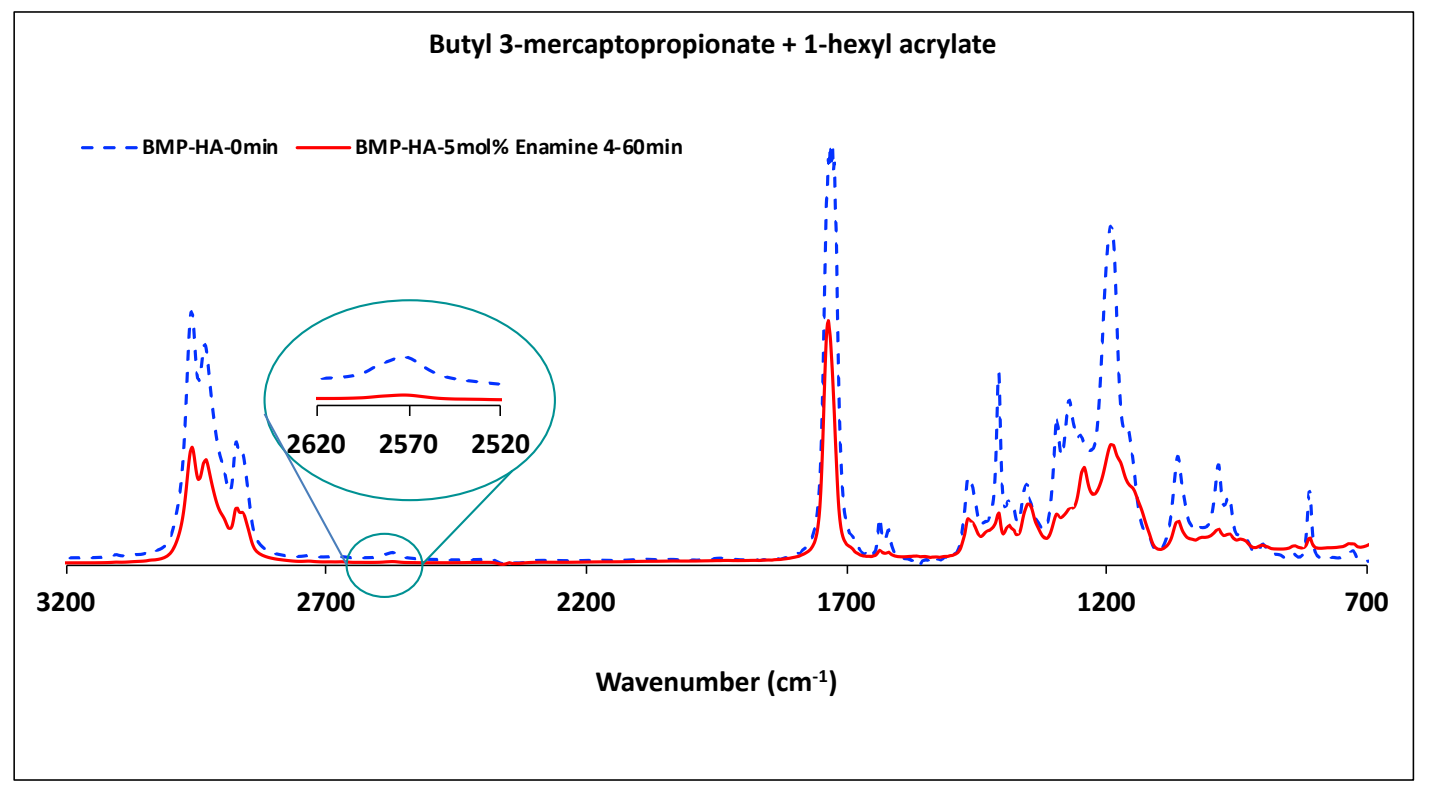

Figure S4. FTIR spectra of BMP and HA in presence of $5 \mathrm{~mol} \%$ Enamine 4 at $0 \mathrm{~min}$ and $60 \mathrm{~min}$. The mixture consists of an initial stoichiometric ratio of 1:1 thiol to vinyl functional group concentration. The functional group conversion of each system was calculated from the peak area of the functional group $\left(2550-2600 \mathrm{~cm}^{-1}\right.$ for thiol). Overall yield obtained was $82 \%$.

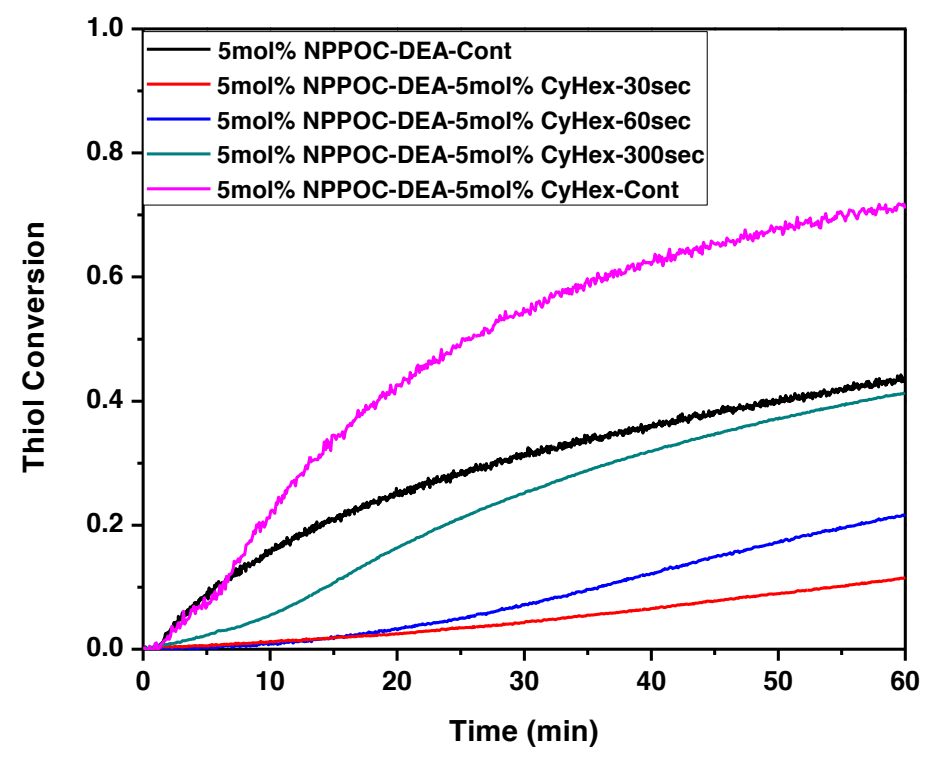

Figure S5. Thiol Conversion versus time as monitored by FT-IR for the model reaction between butyl 3mercaptopropionate (BMP) and 1-hexyl acrylate (HA). The plot demonstrates $5 \mathrm{~mol} \%$ of NPPOC-DEA and its comparison with $5 \mathrm{~mol} \%$ NPPOC-DEA in presence of $5 \mathrm{~mol} \%$ CyHex (cyclohexanone), irradiating for different time intervals, i.e., $30 \mathrm{sec}, 60 \mathrm{sec}, 300 \mathrm{sec}, 60$ minutes continuously. The mixture consists of initial stoichiometric ratio of 1:1 thiol to vinyl functional group concentrations. Each sample was stabilized in the dark for $1 \mathrm{~min}$ and then irradiated with $50 \mathrm{~mW} / \mathrm{cm}^{2} 365 \mathrm{~nm}$ wavelength at ambient temperature. 


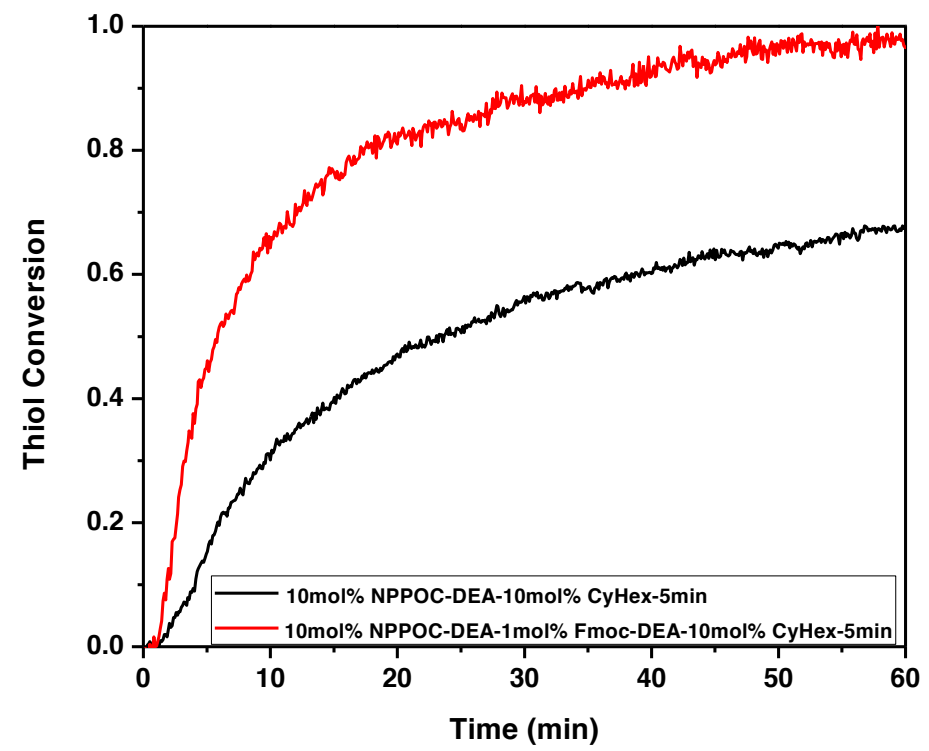

Figure S6. Thiol Conversion versus time as monitored by FT-IR for the model reaction between butyl 3mercaptopropionate (BMP) and 1-hexyl acrylate (HA) (a) $10 \mathrm{~mol} \%$ of NPPOC-DEA in the presence of $10 \mathrm{~mol} \%$ CyHex, and its comparison with $10 \mathrm{~mol} \%$ NPPOC-DEA in the presence of both 1 mol\% Fmoc-DEA and 10 mol\%CyHex (cyclohexanone), irradiating for 5 minutes. The mixture consists of an initial stoichiometric ratio of 1:1 thiol to vinyl functional group concentrations. Each sample was stabilized in the dark for 1 min and then irradiated with $50 \mathrm{~mW} / \mathrm{cm}^{2} 365 \mathrm{~nm}$ wavelength at ambient temperature.

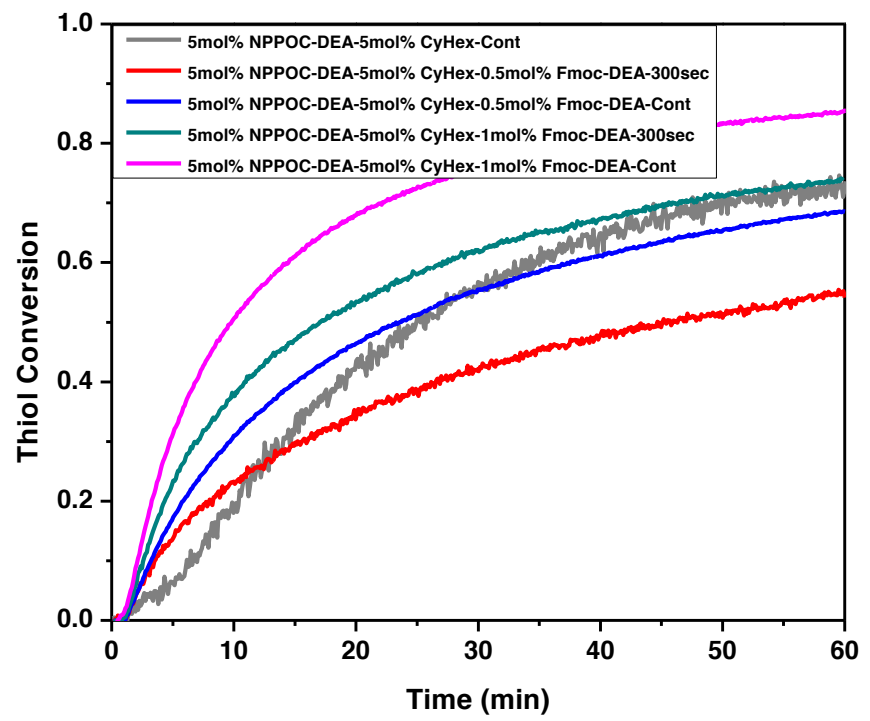

Figure S7. Thiol Conversion versus time as monitored by FT-IR for the model reaction between butyl 3mercaptopropionate (BMP) and 1-hexyl acrylate (HA). Comparison of $5 \mathrm{~mol} \%$ of NPPOC-DEA in the presence of 5 mol\% CyHex, and its comparison with 5mol\% NPPOC-DEA in the presence of both 0.5 or $1 \mathrm{~mol} \%$ Fmoc-DEA and $5 \mathrm{~mol} \% \mathrm{CyHex}$ (cyclohexanone), irradiating for 5 minutes and 30 minutes continuously. The mixture consists of an initial stoichiometric ratio of 1:1 thiol to vinyl functional group concentrations. Each sample was stabilized in the dark for 1 minute and then irradiated with $50 \mathrm{~mW} / \mathrm{cm}^{2} 365 \mathrm{~nm}$ wavelength at ambient temperature 


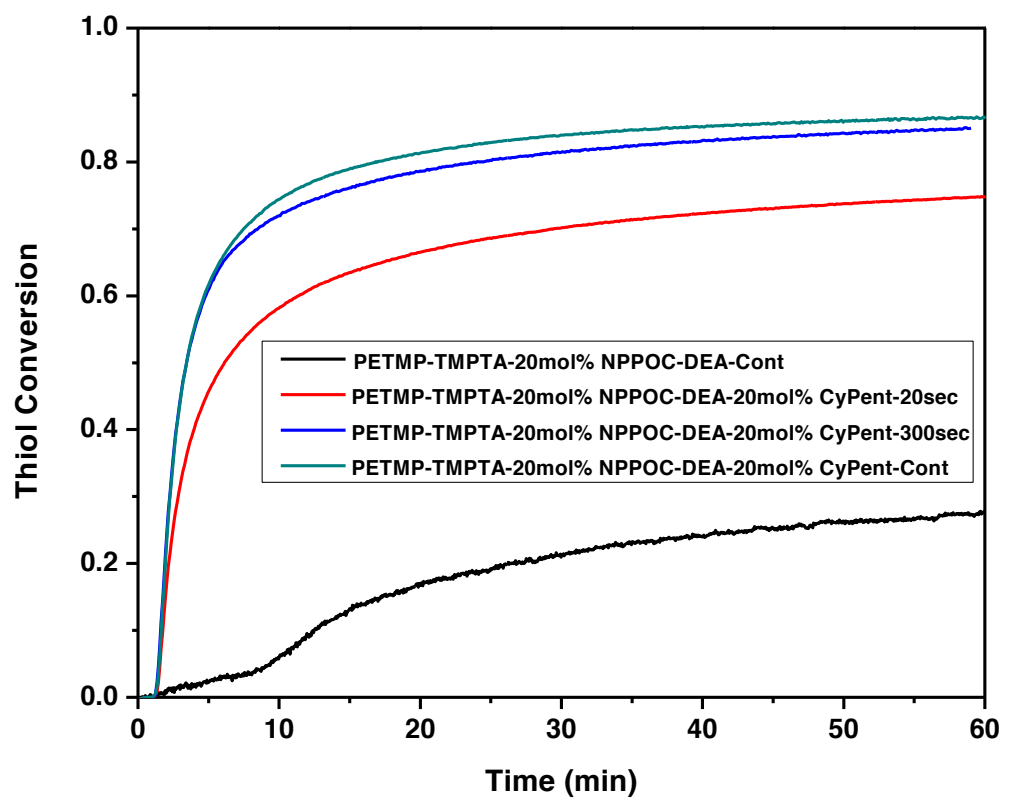

Figure S8. Thiol Conversion versus time as monitored by FT-IR for photopolymerization between PETMP and TMPTA using $20 \mathrm{~mol} \%$ NPPOC-DEA in the presence of $20 \mathrm{~mol} \%$ CyPent(cyclopentanone), irradiating for different time intervals, i.e., $20 \mathrm{sec}, 300 \mathrm{sec}$, and 60 minutes and its comparison with $20 \mathrm{~mol} \%$ of NPPOC-DEA irradiated continuously for 60 minutes without cyclopentanone. The mixture consists of initial stoichiometric ratio of 1:1 thiol to vinyl functional group concentrations. Each sample was stabilized in the dark for $1 \mathrm{~min}$ and then irradiated with 50 $\mathrm{mW} / \mathrm{cm}^{2} 365 \mathrm{~nm}$ wavelength at ambient temperature.

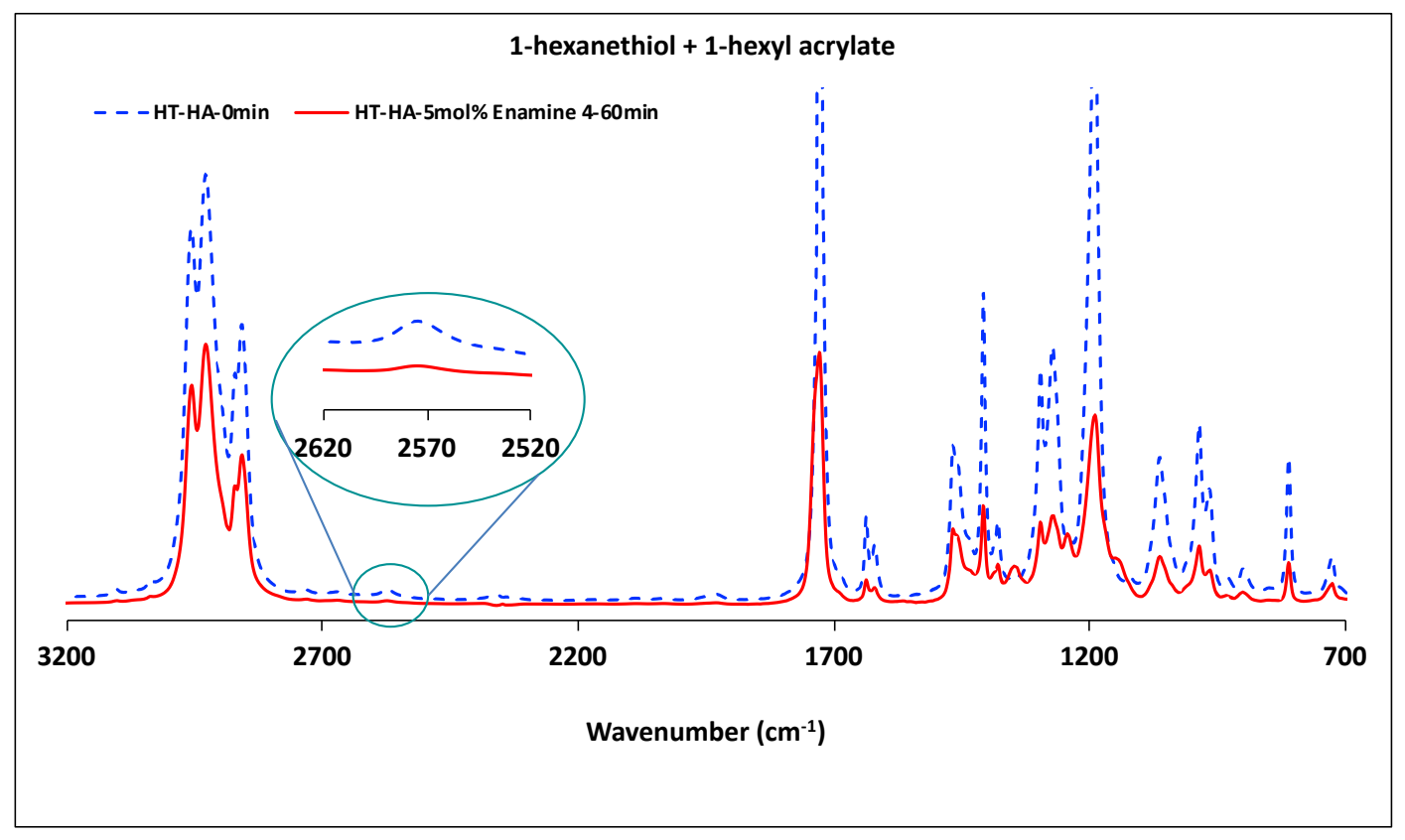

Figure S9. FTIR spectra of 1-hexanethiol and HA in presence of $5 \mathrm{~mol} \%$ Enamine 4 at $0 \mathrm{~min}$ and $60 \mathrm{~min}$. The mixture consists of an initial stoichiometric ratio of 1:1 thiol to vinyl functional group concentration. The functional group conversion of each system was calculated from the peak area of the functional group (2550-2600 $\mathrm{cm}^{-1}$ for thiol). Overall yield obtained was $75 \%$. 


\section{NMR}

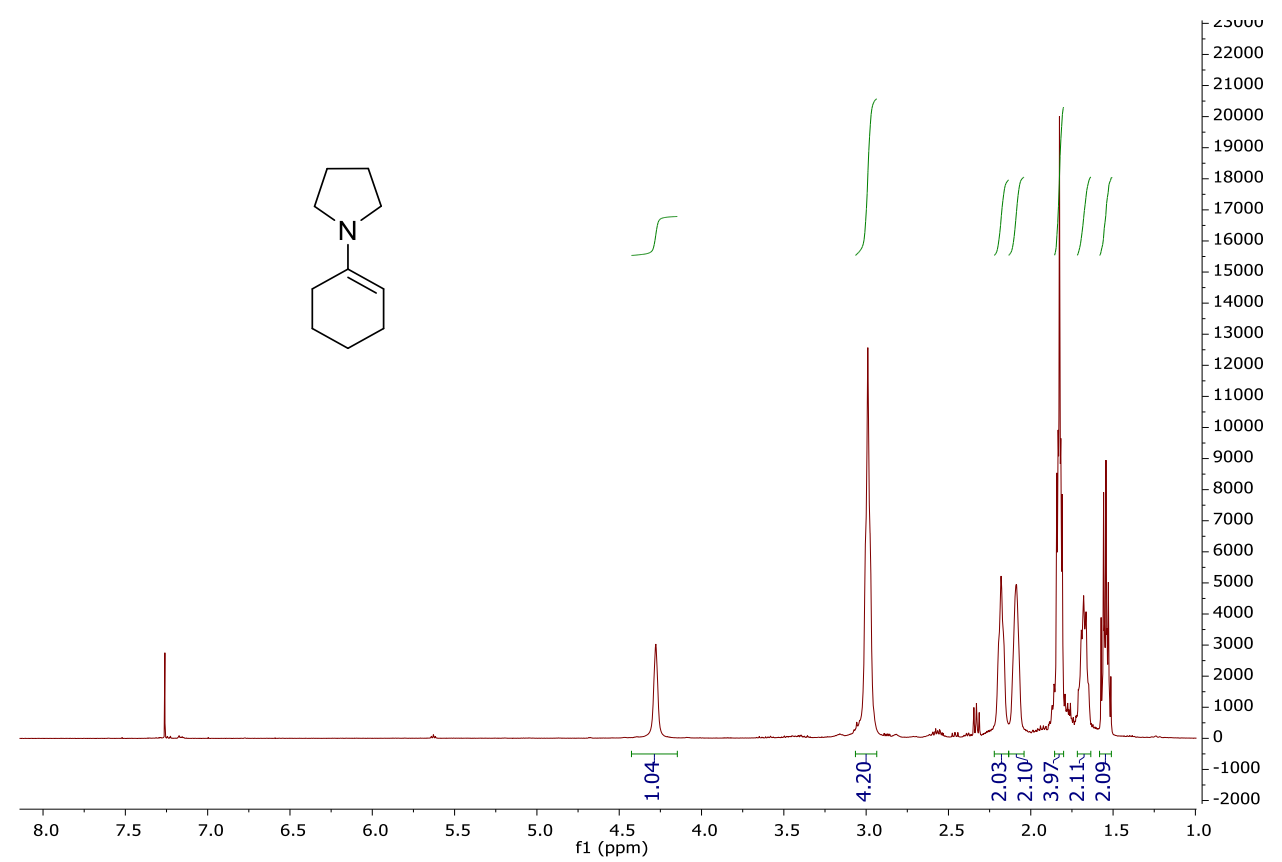

Figure S10. ${ }^{1} \mathrm{H}$ NMR of 1-(1-cyclohexen-1-yl)pyrrolidine

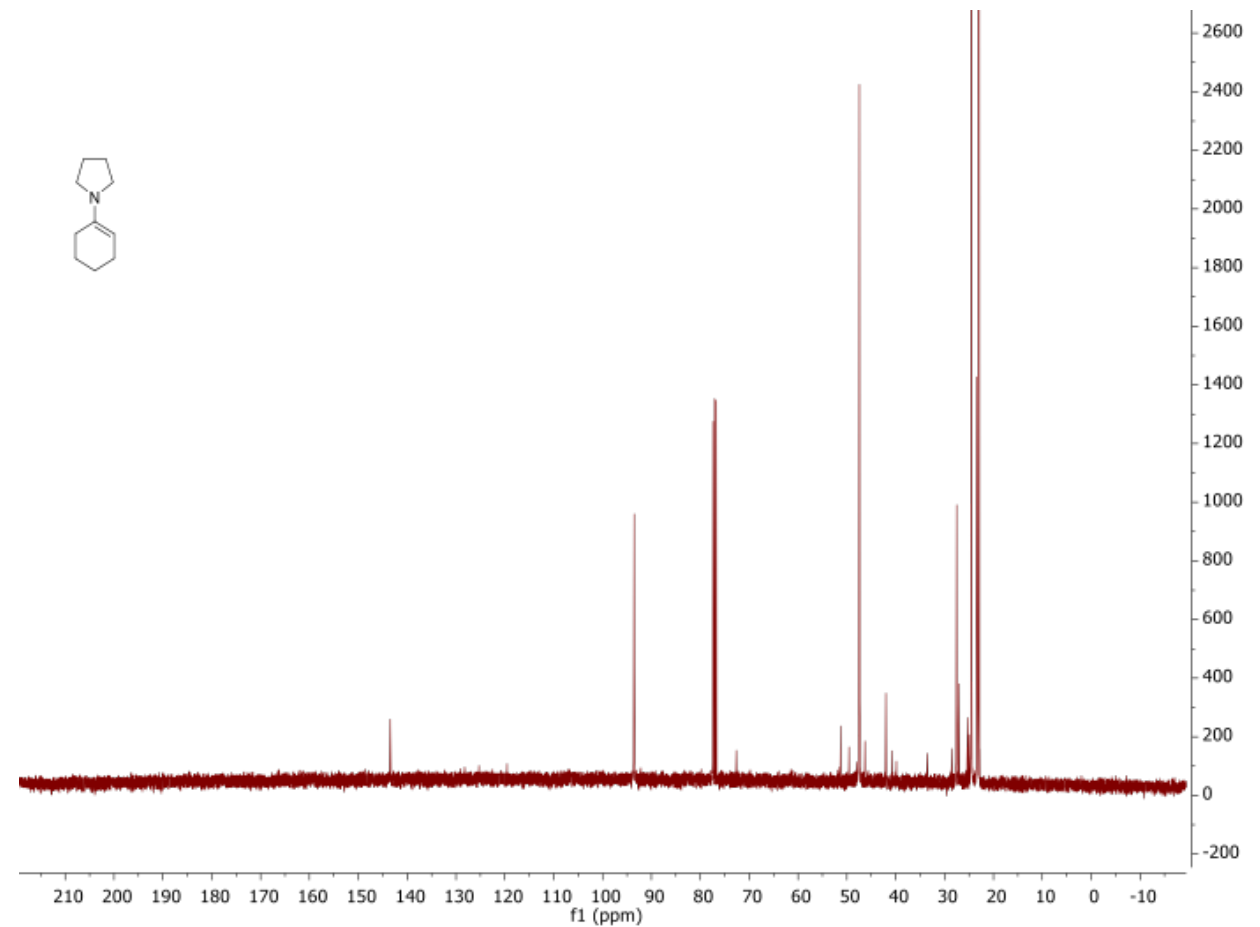

Figure S11. ${ }^{13} \mathrm{C}$ NMR of 1-(1-cyclohexen-1-yl)pyrrolidine. 


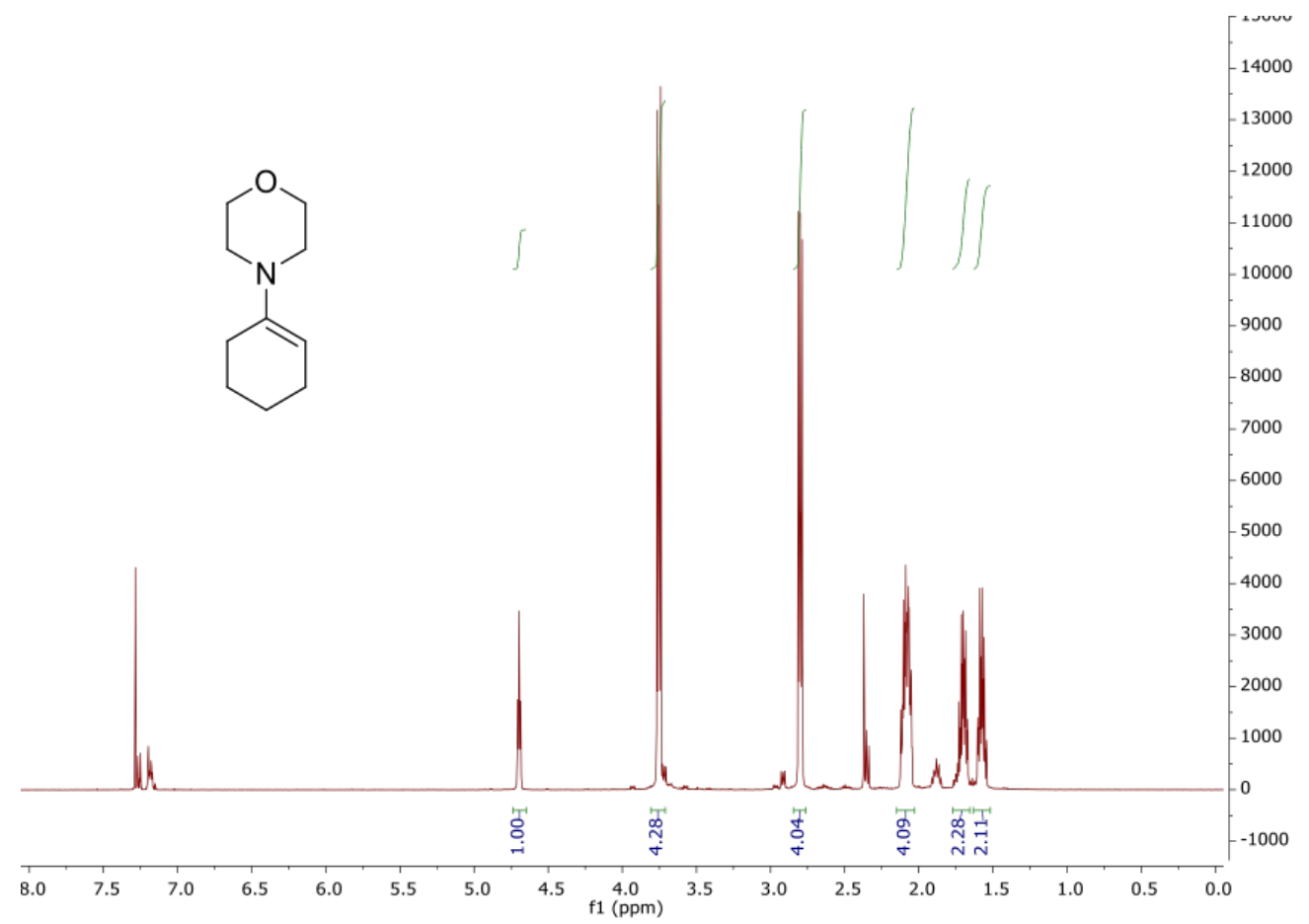

Figure S12. ${ }^{1} \mathrm{H}$ NMR of 4-cyclohexen-1-ylmorpholine.

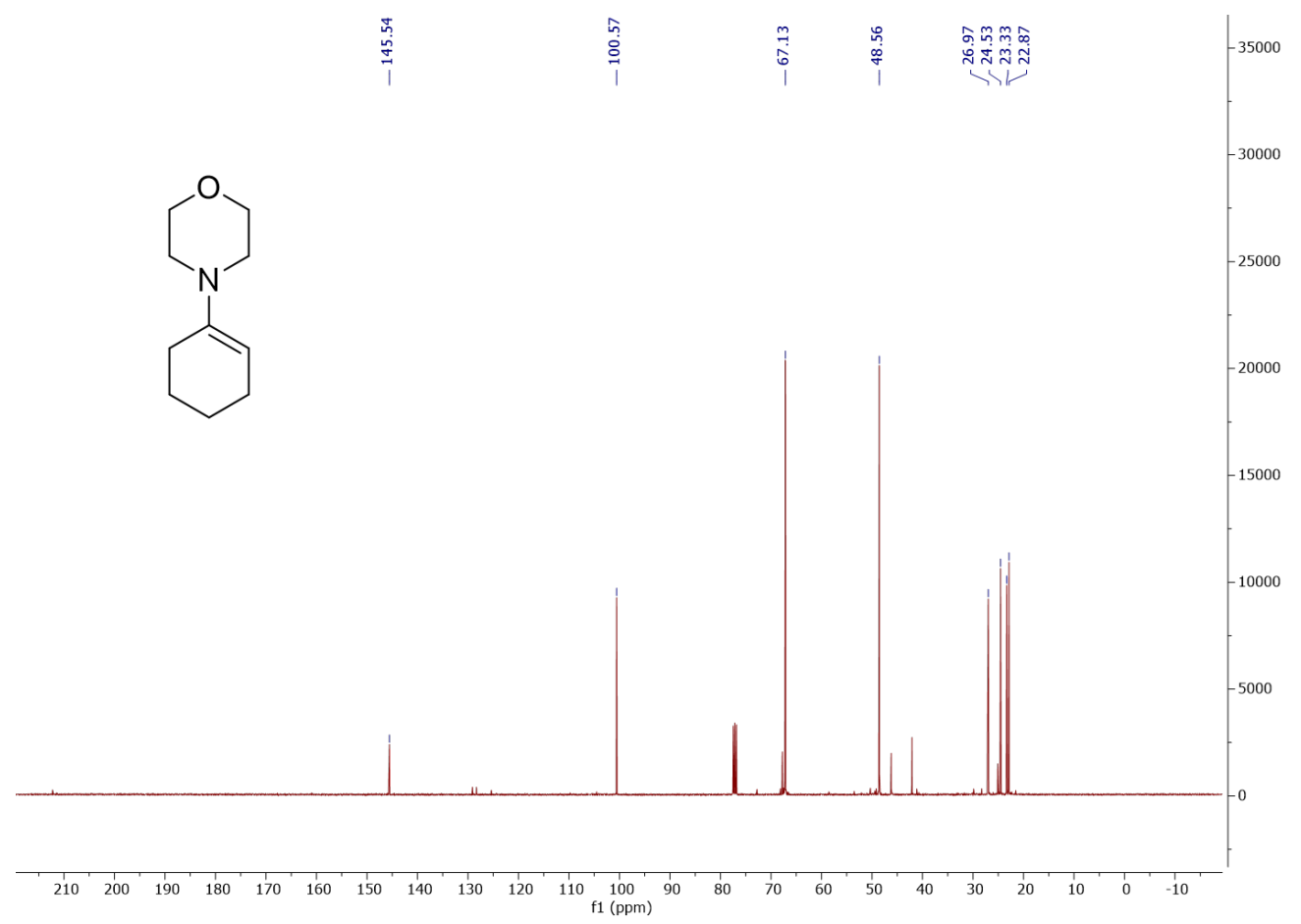

Figure S13. ${ }^{13} \mathrm{C}$ NMR of 4-cyclohexen-1-ylmorpholine. 


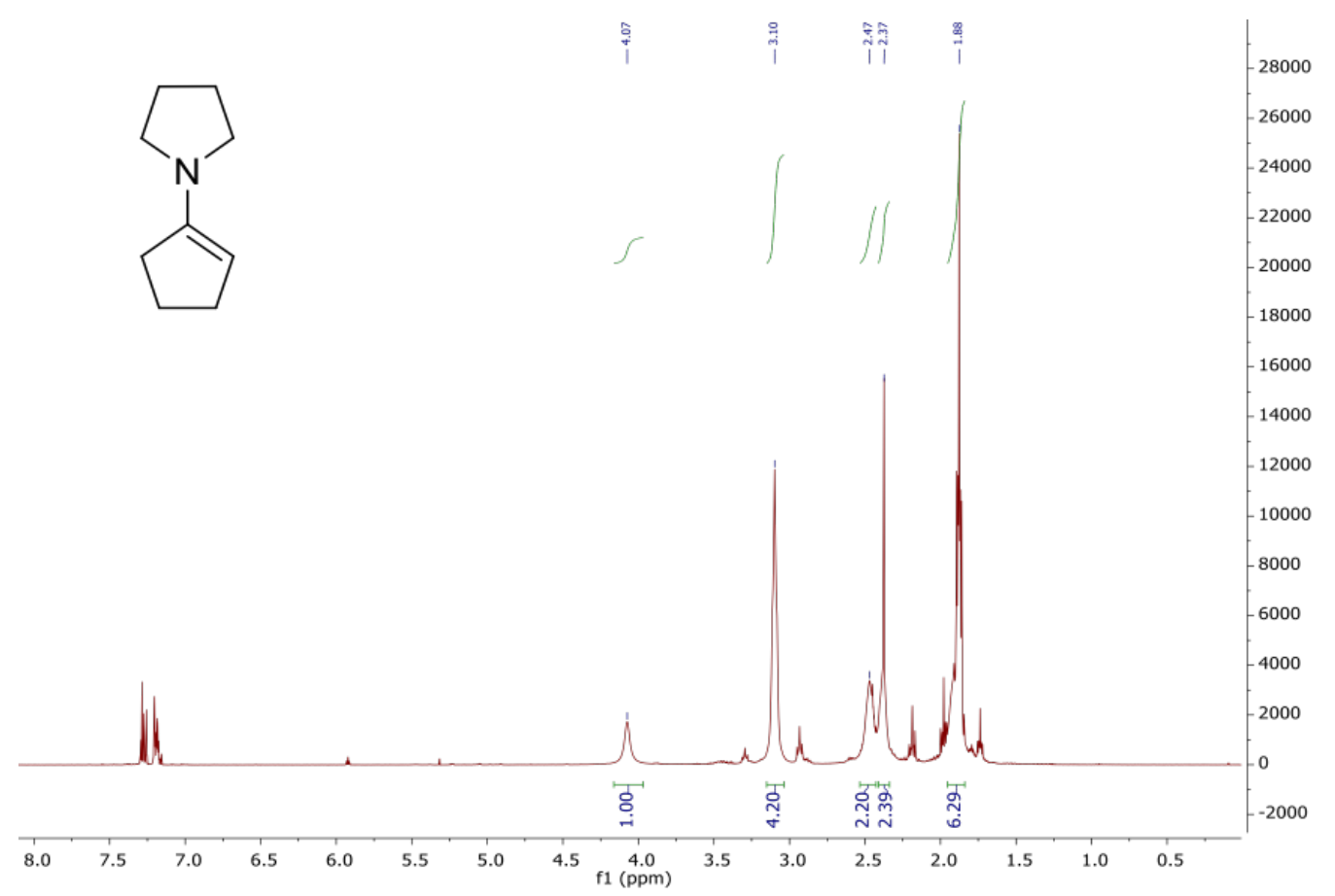

Figure S14. ${ }^{1} \mathrm{H}$ NMR of 1-pyrrolidinocyclopent-1-ene.

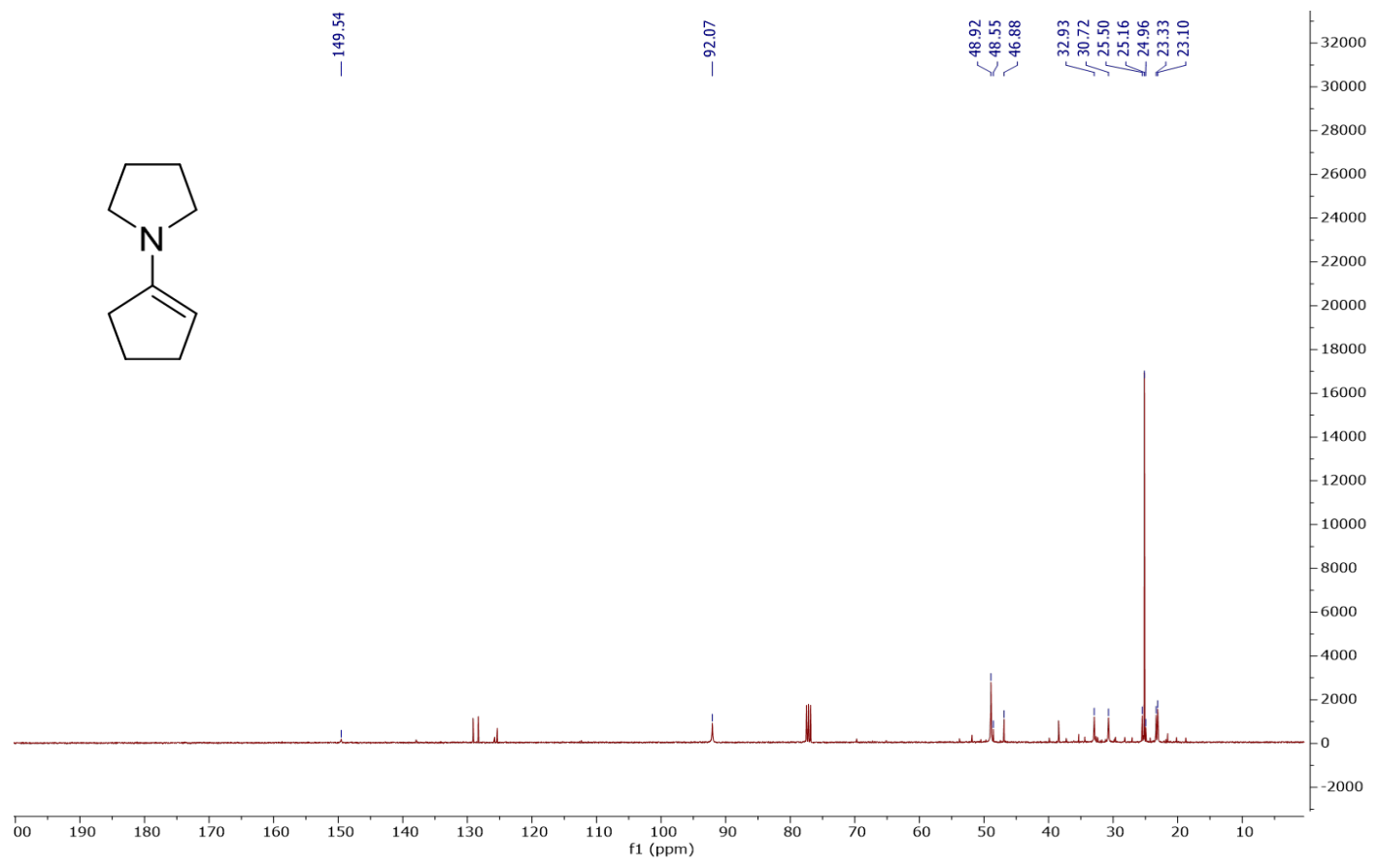

Figure S15. ${ }^{13} \mathrm{C}$ NMR of 1-pyrrolidinocyclopent-1-ene. 


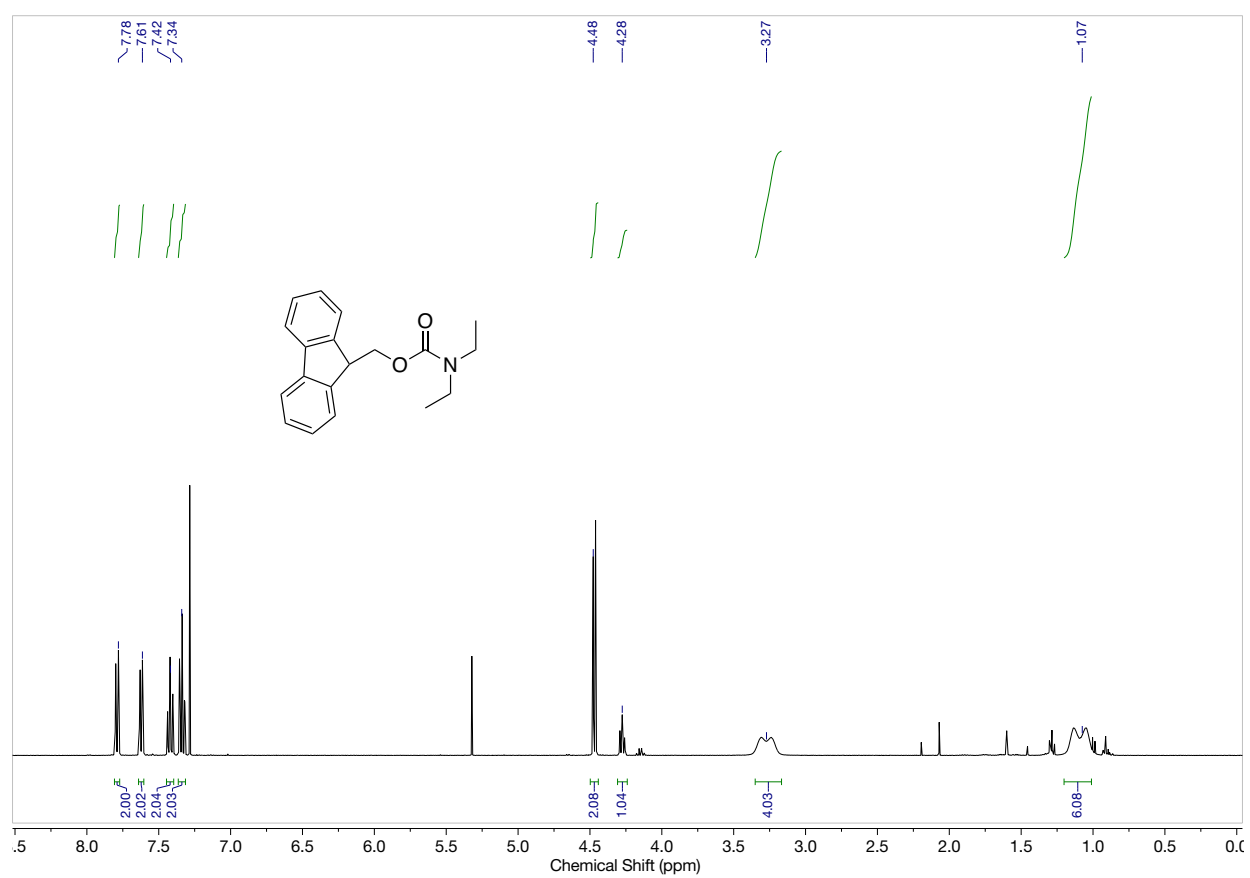

Figure S16. ${ }^{1} \mathrm{H}$ NMR of 1-(9-Fluorenylmethoxycarbonyl)-diethylamine (Fmoc-DEA).

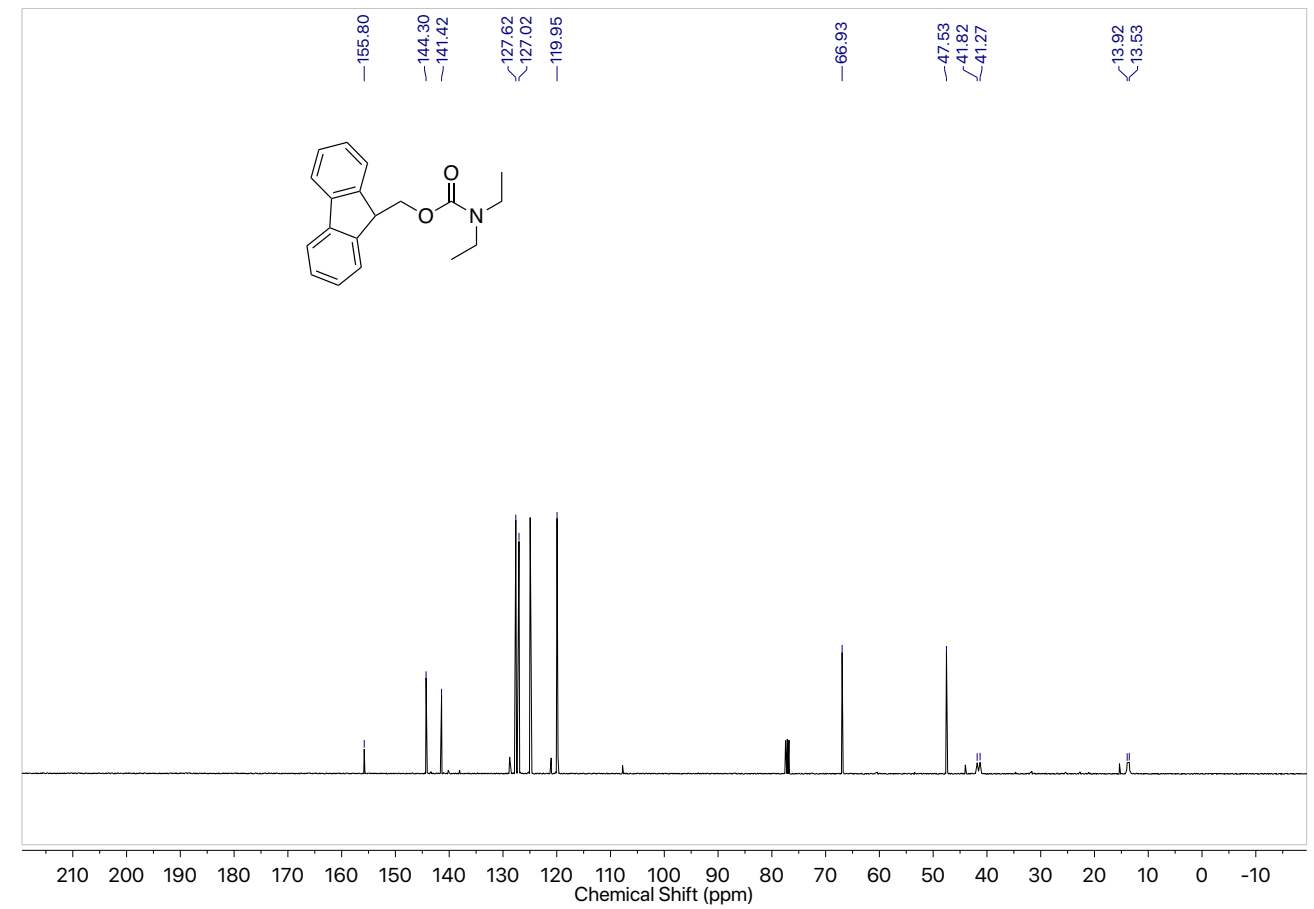

Figure S17. ${ }^{13} \mathrm{C}$ NMR of 1-(9-Fluorenylmethoxycarbonyl)-diethylamine (Fmoc-DEA). 


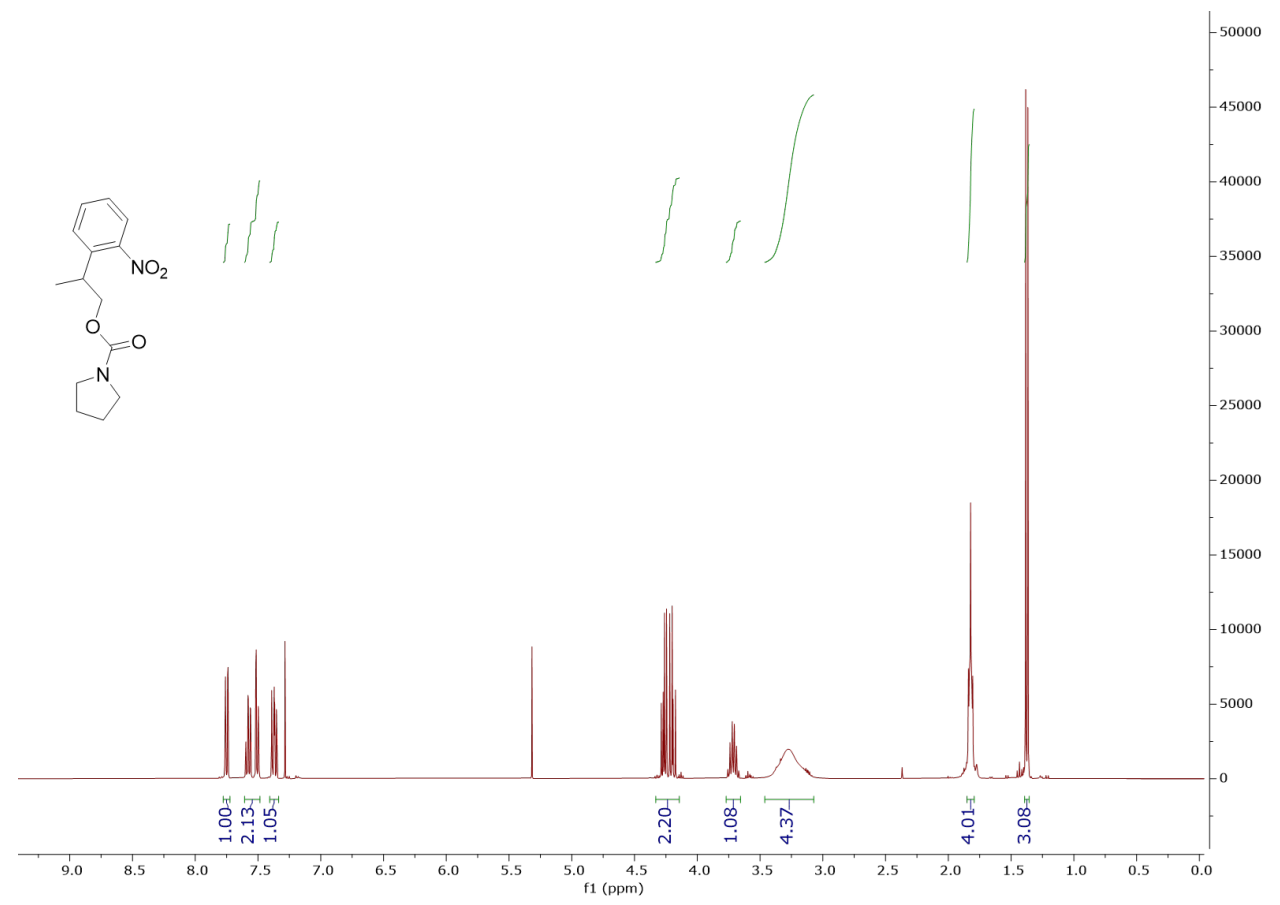

Figure S18. ${ }^{1} \mathrm{H}$ NMR of 2-(2-nitrophenyl)propoxycarbonyl pyrrolidine.

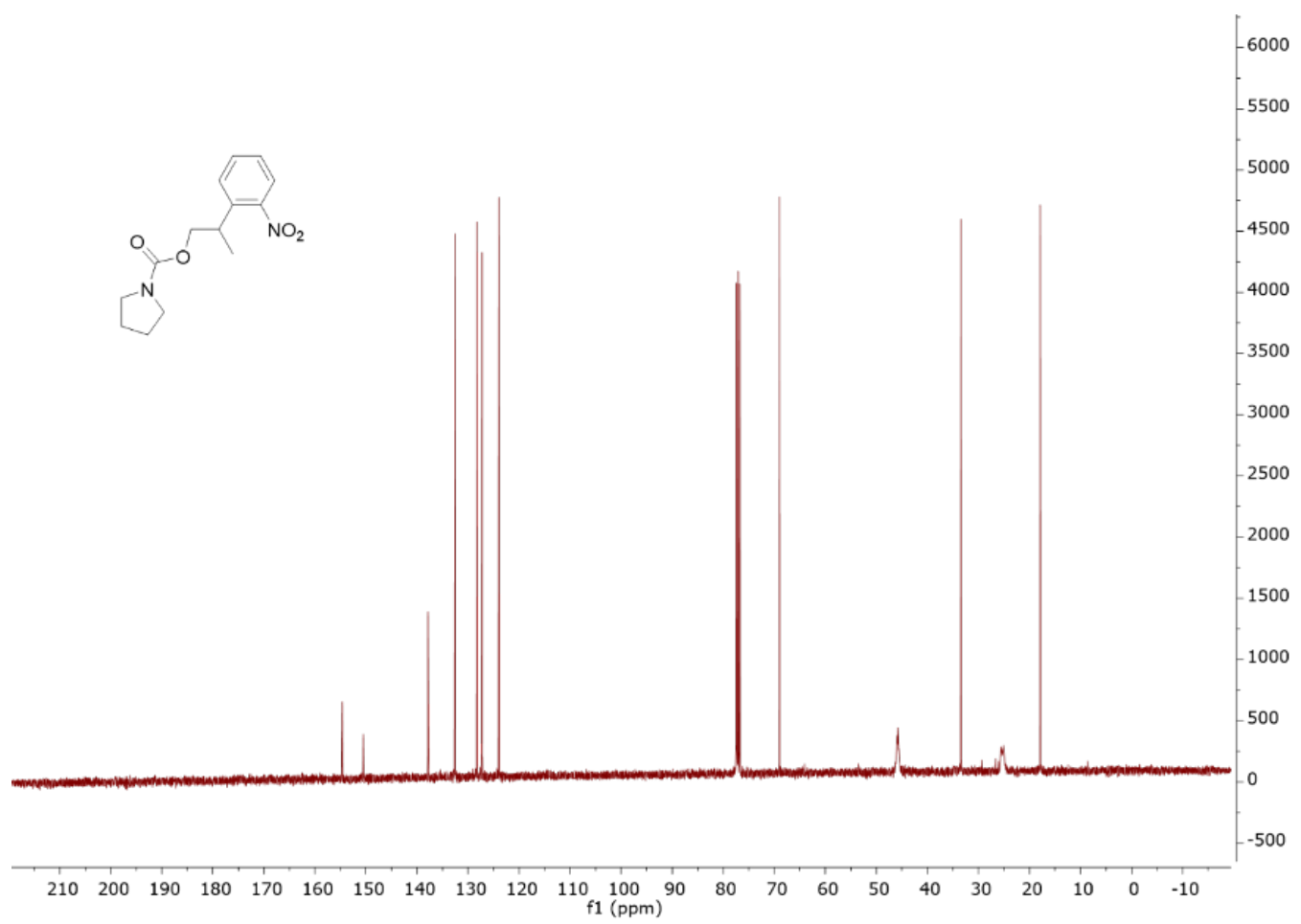

Figure S19. ${ }^{13} \mathrm{C}$ NMR of 2-(2-nitrophenyl)propoxycarbonyl pyrrolidine. 